\title{
COMPARISON OF EFFECT OF PENETRATION ENHANCER ON DIFFERENT POLYMERS FOR DRUG DELIVERY
}

\author{
BHAWANA SETHI ${ }^{*}$, RUPA MAZUMDER ${ }^{2}$
}

1Department of Pharmaceutics, Innovative College of Pharmacy, Plot No. 6, Knowledge Park-II, Greater Noida, Uttar Pradesh 201306, India, ${ }^{2}$ Department of Pharmaceutics, Noida Institute of Engineering and Technology, Greater Noida, Uttar Pradesh 201306, India Email: sethimpharma@gmail.com

Received: 12 Aug 2018, Revised and Accepted: 19 Nov 2018

\section{ABSTRACT}

Objective: Aliskiren hemifumarate is used for the treatment of hypertension. The aim of this research to study the effect on the delivery of drug using natural and synthetic permeation enhancers like limonene, cineol, $\beta$-cyclodextrin, and oleic acid by using different polymers. As different penetration acts differently with polymers.

Methods: Transdermal patches were prepared by the solvent evaporation technique. The controlled release polymers were used for the preparation of patches. The patches were prepared with different polymers and different plasticizer. The drug and polymer interaction study was performed by Fourier transform infrared spectra. In vitro permeation studies were conducted using pretreated cellophane membrane using franz diffusion cell.

Results: The prepared patches were evaluated for in vitro drug release, and the release profile was varied from $52.32 \%$ PGH (oleic acid) to $87.63 \%$ $\mathrm{B}$ (cineol). The permeability coefficient was found in the range of 5.82 to $8.32 \mathrm{~cm} / \mathrm{h}$, and corresponding flux was found between 281.61 to 729.08 $\mu \mathrm{g} / \mathrm{cm}^{2} / \mathrm{h}$ on the prepared patches and statistical analysis performed using t-test $(\mathrm{p}<0.005)$.

Conclusion: On the basis of the obtained results, it was concluded that patch prepared using methocel $\mathrm{k} 15 \mathrm{~m}$ as a polymer, glycerin as plasticizer and cineol as a permeation enhancer shows the maximum release. The increase in the release due to increase in the flux.

Keywords: Transdermal patch, Penetration enhancer, Permeability coefficient, Flux

(C) 2019 The Authors. Published by Innovare Academic Sciences Pvt Ltd. This is an open-access article under the CC BY license (http://creativecommons.org/licenses/by/4.0/) DOI: http://dx.doi.org/10.22159/ijap.2019v11i1.29082

\section{INTRODUCTION}

Human skin is the most complex organ and provides an efficient barrier for transfer of the molecules. It prevents any loss of essential physiological substances from the body. The barrier offered by skin causes the difficulty for transdermal delivery of therapeutic agents $[1,2]$. The absorption through the skin was increased by changing the barrier properties of the skin through rupturing the skin barrier properties. These are the agent which helps in the promotion of the absorption of drugs through the skin temporarily by transiently enhancing the skin permeability [3]. The permeation enhancers are inert and nontoxic substances having no therapeutic value but enhance the sorption of the drug through the skin by different approaches to permeation enhancement, such as chemical approaches which cause chemical changes by using chemicals such as terpenes, surface active agent and spans, etc. The other method involves like physical enhancement, biochemical enhancement, supersaturation enhancement, and bio-convertable prodrug. Ideally, reversible changes in the skin should be made of permeation enhancers without damaging viable cells $[4,5]$.

There are various mechanisms to promote the skin penetration. The penetration is mainly increased by the interaction of the enhancers with the polar head group of the lipids. The penetration of hydrophilic drugs occurred by lipid-lipid head group interaction and disruption, of the packing arrangement of the lipids. The main function of penetration enhancers by lipid disruption, protein modification, and partitioning promotion. In lipid disruption, the enhancer changes the structure of the stratum corneum of lipid organization and make it permeable to drugs e. g azone, terpene, dimethylsulfoxide. In protein modification the open up the dense protein structure and make it permeable e. g dimethyl sulfoxide and in partitioning promotion, they change the solution properties of horny layer and thus increase the partitioning of drugs, coenhancer [6-9].

Ideal characteristics of permeation enhancers: compatibility with the drug, have good solvent properties, doesn't show any adverse pharmacological activity inside the body, doesn't impart any color, odor, taste, chemically and physically stable.

The penetration enhancers are classified into three main types: drug vehicle based, chemical penetration enhancers and physical penetration enhancers.

In the present studies enhancer from different classes were selected for studies. The main function of the chemical enhancers to reversibly disrupt the various barriers of skin and known as absorption promoters which can enhance the flux. The selected enhancers were natural (limonene, cineol), surfactant (dimethyl oxide), complex forming ( $\beta$-cyclodextrin) and span (oleic acid). Each enhancer was evaluated with different polymer and plasticizer [10-12]

The objective of the study was to compare the release effect of different permeation enhancer (natural and synthetic) from patches prepared using a different polymer with varying concentration and plasticizer. The best permeation enhancer was selected on the basis of the release of the drug from the patches.

\section{MATERIALS AND METHODS}

\section{Materials}

Aliskiren hemifumarate was a gift from the dr. morepen laboratories (India). The excipients like methocel $(\mathrm{k} 15 \mathrm{~m}, \mathrm{k} 100 \mathrm{~m})$, ethocel $(\mathrm{k}$ $15 \mathrm{~m}, \mathrm{k} 100 \mathrm{~m}$ ) was received as a gift sample from colorcon mumbai. The HPLC grade reagents and solvents procured commercially.

Transdermal films containing aliskiren hemifumarate were prepared by evaporation of solvent technique using mercury substrate with a different polymer and different plasticizers.

\section{Fourier transform infrared spectroscopy}

To identify the interaction between the drug and the utilized polymers, infrared spectroscopy of pure drug and its physical 
mixture with polymers was carried using infrared spectroscopy; the range selected was from $400 \mathrm{~cm}^{-1}$ to $4000 \mathrm{~cm}^{-1}$.

\section{Preparation of transdermal patches using different permeation} enhancer

The patches were prepared by solvent evaporation method the detail on formulation provided in table 1 . The plasticizers used in the formulation were glycerin and propylene glycol at a concentration of $150 \% \mathrm{w} / \mathrm{w}$. About $5 \mathrm{ml}$ of the solution was poured on the mercury substrate. The evaporation of the solvent was controlled by inverting the funnel over the poured solution in the mould. After 6-8 $\mathrm{h}$, the dried patches were removed from the mould and packed in aluminum foil and placed over fused calcium chloride in desiccators at room temperature.

Table 1: Composition of transdermal patches along with details of polymers, plasticizer and permeation enhancers

\begin{tabular}{|c|c|c|c|c|c|c|}
\hline $\begin{array}{l}\text { S. } \\
\text { No. }\end{array}$ & Formulation & Code & $\begin{array}{l}\text { Composition } \\
\text { (drug: polymer) }\end{array}$ & $\begin{array}{l}\text { Plasticizer } \\
(\% \mathrm{w} / \mathrm{w})\end{array}$ & $\begin{array}{l}\text { Permeation } \\
\text { enhancer }\end{array}$ & Casting solvent \\
\hline 1 & Methocel K 15 M & $\mathrm{B}$ & $1: 1.5$ & $150^{*}$ & Limonene & Chloroform: Dichloromethane: Ethanol (2:2:1) \\
\hline 2 & Methocel K 100 M & $\mathrm{E}$ & $1: 1.5$ & & Cineol & -- \\
\hline 3 & Ethocel standard 10 & $\mathrm{~J}$ & $1: 1$ & & $\beta$-Cyclodextrin & Chloroform \\
\hline 4 & Methocel K 15 M & PGB & $1: 1.5$ & $150^{\#}$ & Oleic acid & Chloroform: Dichloromethane: Ethanol(2:2:1) \\
\hline 5 & Methocel K 100 M & PGD & $1: 1$ & & & Chloroform: Dichloromethane: Ethanol(2:2:1) \\
\hline 6 & Ethocel standard 4 & $\mathrm{PGH}$ & $1: 1.5$ & & & Chloroform \\
\hline
\end{tabular}

*Glycerin used as a plasticizer. \# Propylene glycol used as a plasticizer.

\section{Evaluation of transdermal patches}

The prepared patches were subjected to physical and chemical evaluation.

\section{Weight variation}

It was determined by weighing three patches of each formulation.

\section{Thickness}

The thickness of patches can be measure from different locations.

\section{Percentage moisture absorption}

The weighed films were placed in a desiccator having $100 \mathrm{ml}$ of saturated aluminum chloride solution, maintaining $79.50 \% \mathrm{RH}$ percentage moisture absorption calculated after $3 \mathrm{~d}$ using the formula.

Percentage moisture absorption $=$

$$
\frac{\text { Final weight }- \text { Initial weight }}{\text { Initial weight }} \times 100
$$

\section{Percentage moisture loss}

The accurately weighed films were kept in a desiccator containing anhydrous calcium chloride. The moisture loss after $3 \mathrm{~d}$ was calculated using the formula.

Percentage moisture loss $=$

$$
\frac{\text { Final weight }- \text { Initial weight }}{\text { initial weight }} \times 100
$$

\section{Water vapour transmission rate}

The amount of water vapour transmitted was calculated using the formula [13-18].

Water vapour transmission rate $=$

$$
\frac{\text { Final weight }- \text { Initial weight }}{\text { Time } \times \text { Area }} \times 100
$$

In vitro permeation studies of aliskiren hemifumarate using pretreated cellophane membrane

The permeation of aliskiren hemifumarate was determined using franz diffusion cell. The membrane was mounted onto the diffusion cell with the one side facing the donor compartment and other end facing the receptor compartment. The receiving compartment was filled with dissolution media. For studies, the pretreated cellophane membrane was used and patches were cut into the pieces of $2.5 \mathrm{~cm}$ diameter and applied to the membrane. Finally, the receptor solution was withdrawn after different time interval like $0,1,2,3,4,5,6,7,8,9,10$ and $24 \mathrm{~h}$ and the sample analyzed using ultraviolet spectrophotometer at $269 \mathrm{~nm}$.

\section{Data analysis}

The cumulative amount of the drug penetrated through membrane was plotted against time from the slope, permeability coefficient and flux.

\section{Permeability coefficient calculation}

The data analysis was performed on data obtained from in vitro release and analysed by applying factor for volume correction.

Permeability coefficient is defined as the amount of the drug passage through the skin in a particular time $\left(\mu \mathrm{g} / \mathrm{cm}^{2} / \mathrm{h}\right)$. The permeability coefficient was calculated from the slope of the graph of percentage drug transported with time $[19,20]$.

$$
\mathrm{PC}=\text { Slope } \times \mathrm{Vd} / \mathrm{S}
$$

$V \mathrm{~d}$ is the volume of the donor solution in $\mathrm{ml}$;

$\mathrm{S}$ is the surface area on which patch applied in $\mathrm{cm}$.

Flux is defined as the cumulative amount of the drug passes through the unit of the skin surface in specified time.

$$
\text { Flux }=\text { PC } \times \text { concentration of donor solution }\left(\frac{\mathrm{mg}}{\mathrm{ml}}\right)
$$

\section{RESULTS}

The aim of the present study to evaluate the effect of natural and

\begin{tabular}{|c|c|c|c|c|c|c|c|c|c|c|}
\hline \multirow[t]{2}{*}{ Formulation code } & \multicolumn{2}{|c|}{ Weight variation (mg) } & \multicolumn{2}{|c|}{$\begin{array}{l}\text { Percentage moisture } \\
\text { absorption }\end{array}$} & \multicolumn{2}{|c|}{$\begin{array}{l}\text { Percentage } \\
\text { moisture loss }\end{array}$} & \multicolumn{2}{|c|}{$\begin{array}{l}\text { Water vapor transmission } \\
\text { rate }\left(\mathrm{g} / \mathrm{cm}^{2} / \mathrm{h}\right)\end{array}$} & \multicolumn{2}{|c|}{$\begin{array}{l}\text { Thickness } \\
\text { (mm) }\end{array}$} \\
\hline & Mean & SD & Mean & SD & Mean & SD & Mean & SD & Mean & SD \\
\hline B & 58.33 & 0.58 & 5.16 & 1.063 & 3.85 & 0.237 & 0.54 & 0.30 & 0.066 & 0.005 \\
\hline $\mathrm{E}$ & 52.00 & 2.65 & 5.59 & 1.506 & 4.96 & 0.892 & 0.46 & 0.02 & 0.057 & 0.003 \\
\hline $\mathrm{J}$ & 49.00 & 2.00 & 6.14 & 0.290 & 5.08 & 0.751 & 0.48 & 0.04 & 0.061 & 0.002 \\
\hline PGB & 57.33 & 0.58 & 4.93 & 0.15 & 4.32 & 0.78 & 0.85 & 0.09 & 0.07 & 0.00 \\
\hline PGD & 40.67 & 0.58 & 3.87 & 0.78 & 3.14 & 0.40 & 0.83 & 0.09 & 0.05 & 0.00 \\
\hline PGH & 52.00 & 0.00 & 6.11 & 0.44 & 4.77 & 1.17 & 0.52 & 0.04 & 0.05 & 0.00 \\
\hline
\end{tabular}
synthetic permeation enhancer on the release profile of the drug through transdermal patches. Patches prepared using various synthetic polymers with a different plasticizer.

Table 2: Result showing the effect of physicochemical properties of patches prepared using glycerin as a plasticizer

Results are expressed as mean $\pm \mathrm{SD} ; \mathrm{n}=3$ 
Table 3: The in vitro permeation studies, permeability coefficient and flux from various formulations

\begin{tabular}{|c|c|c|c|c|}
\hline Formulation & Cumulative \% permeated & SD & Permeability coefficient $(\mathrm{cm} / \mathrm{h})$ & Flux $\left(\mu \mathrm{g} / \mathrm{cm}^{2} / \mathrm{h}\right)$ \\
\hline B (limonene) & 72.45 & 0.01 & 6.72 & 486.70 \\
\hline $\mathrm{B}($ cineol) & 87.63 & 0.23 & 8.32 & 729.08 \\
\hline $\mathrm{B}(\beta$-cyclodextrin $)$ & 67.38 & 1.56 & 6.67 & 449.48 \\
\hline B (oleic acid) & 62.70 & 1.01 & 6.31 & 395.71 \\
\hline E (limonene) & 61.66 & 0.03 & 6.20 & 382.59 \\
\hline E (cineol) & 78.68 & 0.04 & 7.73 & 608.12 \\
\hline $\mathrm{E}(\beta$-cyclodextrin $)$ & 65.64 & 0.50 & 6.72 & 440.97 \\
\hline E (oleic acid) & 68.28 & 0.13 & 6.80 & 464.46 \\
\hline J (limonene) & 75.79 & 0.04 & 7.60 & 575.67 \\
\hline $\mathrm{J}$ (cineol) & 74.44 & 0.03 & 7.57 & 563.74 \\
\hline J ( $\beta$-cyclodextrin) & 64.20 & 1.79 & 6.49 & 416.59 \\
\hline J (oleic acid) & 61.84 & 0.04 & 6.16 & 380.90 \\
\hline PGB (limonene) & 73.32 & 0.10 & 7.22 & 529.04 \\
\hline PGB (cineol) & 75.33 & 0.05 & 7.32 & 551.57 \\
\hline PGB ( $\beta$-cyclodextrin) & 75.89 & 0.02 & 7.79 & 590.93 \\
\hline PGB (oleic acid) & 71.85 & 0.06 & 7.30 & 524.64 \\
\hline PGD (limonene) & 72.66 & 0.06 & 7.38 & 535.94 \\
\hline PGD (cineol) & 76.83 & 0.00 & 7.68 & 589.71 \\
\hline PGD ( $\beta$-cyclodextrin) & 61.84 & 0.04 & 6.45 & 398.66 \\
\hline PGD (oleic acid) & 59.55 & 0.80 & 6.33 & 376.78 \\
\hline PGH (limonene) & 74.23 & 0.02 & 7.34 & 544.54 \\
\hline PGH (cineol) & 75.24 & 0.01 & 7.57 & 569.29 \\
\hline PGH ( $\beta$-cyclodextrin $)$ & 59.24 & 0.27 & 5.92 & 350.43 \\
\hline PGH (oleic acid) & 52.32 & 0.21 & 5.38 & 281.61 \\
\hline
\end{tabular}

Results are expressed as mean $\pm S D ; n=3$

\section{DISCUSSION}

\section{Fourier transform infrared spectroscopy}

The compatibility between drug and polymers was studied by fourier transform infrared spectra. The spectra were recorded to assess the interaction between polymers and the drug as shown in fig. 1 and 2. The infra-red spectrum shows no distinctive chemical and physical interaction with each other for scanning at a wavelength from 400 to $4000 \mathrm{~cm}^{-1}$.

\section{Weight variation}

The average weight of the formulations was ranged from 40.67$58.33 \mathrm{mg}$. The difference in weight depends on varying polymer concentration and grade of the polymer.

\section{Percentage moisture absorption}

Moisture absorption studies indicated that the increase in the concentration of hydrophilic polymer was directly proportional to the increase in moisture content and moisture uptake of the patches. The moisture content of the prepared formulation was low, which could help the formulations remain stable and reduce brittleness during long-term storage. The moisture uptake of the formulation was also low, which could protect the formulations from microbial contamination and reduce bulkiness. The percentage moisture absorption varies from 3.87 to 6.14 for patches.

\section{Percentage moisture loss}

The percentage moisture loss from patches was ranging from 3.14 to 5.08 .

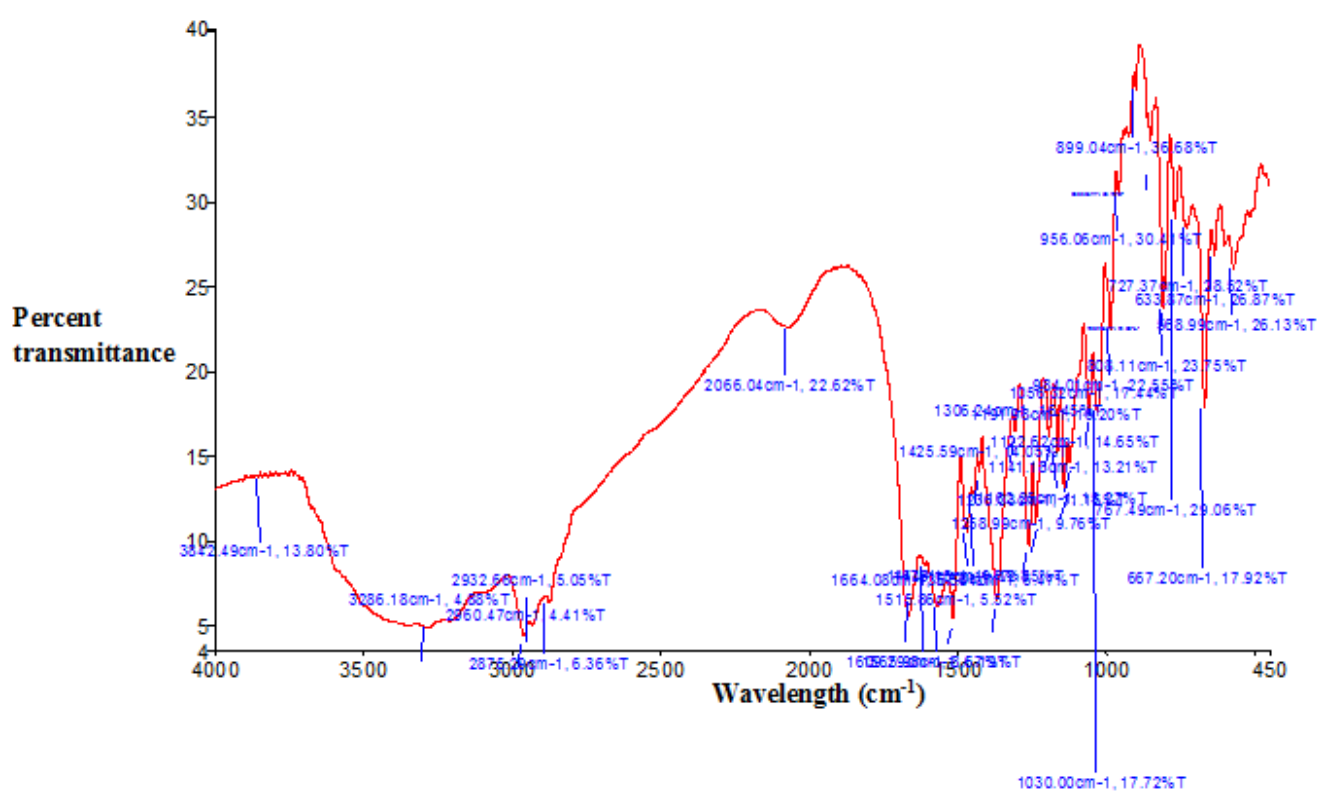

Fig. 1: FTIR spectra of aliskiren hemifumarate 


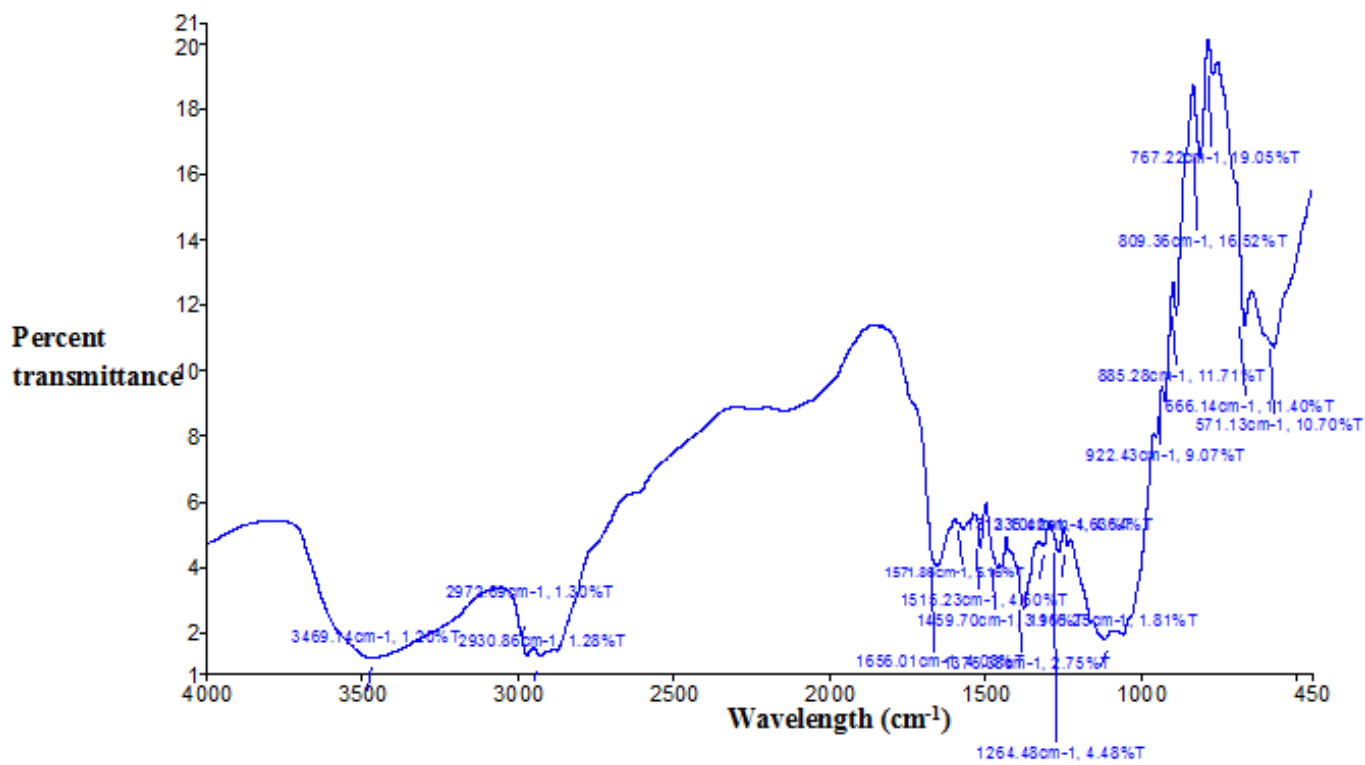

Fig. 2: FTIR spectra of aliskiren hemifumarate with polymer

\section{Thickness}

The thickness of the three patches varies from 0.05 to $0.066 \mathrm{~mm}$.

\section{Water vapour transmission rate}

The water vapour transmission rate from patches was range from 0.46 to 0.85 .

\section{In vitro permeation studies}

The concentration of permeation enhancer was decided on the basis of published literature. Diffusion studies were performed using locally fabricated franz diffusion cell through pretreated cellophane membrane. Each permeation enhancer was formulated with a varying concentration of polymer, different polymers, and different plasticizer.
The in vitro release is helpful in predicting that how will it behave in the body. The cumulative percentage of in vitro release in $24 \mathrm{~h}$ by different enhancers was shown in table 2 and ranged from 52.32\% PGH (oleic acid) to $87.63 \% \mathrm{~B}$ (cineol). The statistical analysis was performed, and results were analyzed using $\mathrm{t}$-test $(\mathrm{p}<0.005)$. The difference was observed on in vitro release of drug between the formulations prepared using different plasticizer and a varying concentration of polymer. The highest release of the drug was observed in the formulation prepared using polymer methocel $\mathrm{k} 15 \mathrm{~m}$ and permeation enhancer cineol.

\section{Permeability coefficient and flux}

The permeability coefficient and flux were calculated. The values ranged from 5.82 to $8.32 \mathrm{~cm} / \mathrm{h}$ for permeability and flux ranged from 281.61 to $729.08 \mu \mathrm{g} / \mathrm{cm}^{2} / \mathrm{h}$. The highest release was obtained from methocel $\mathrm{k} 15 \mathrm{~m}$ using cineol as penetration enhancer.

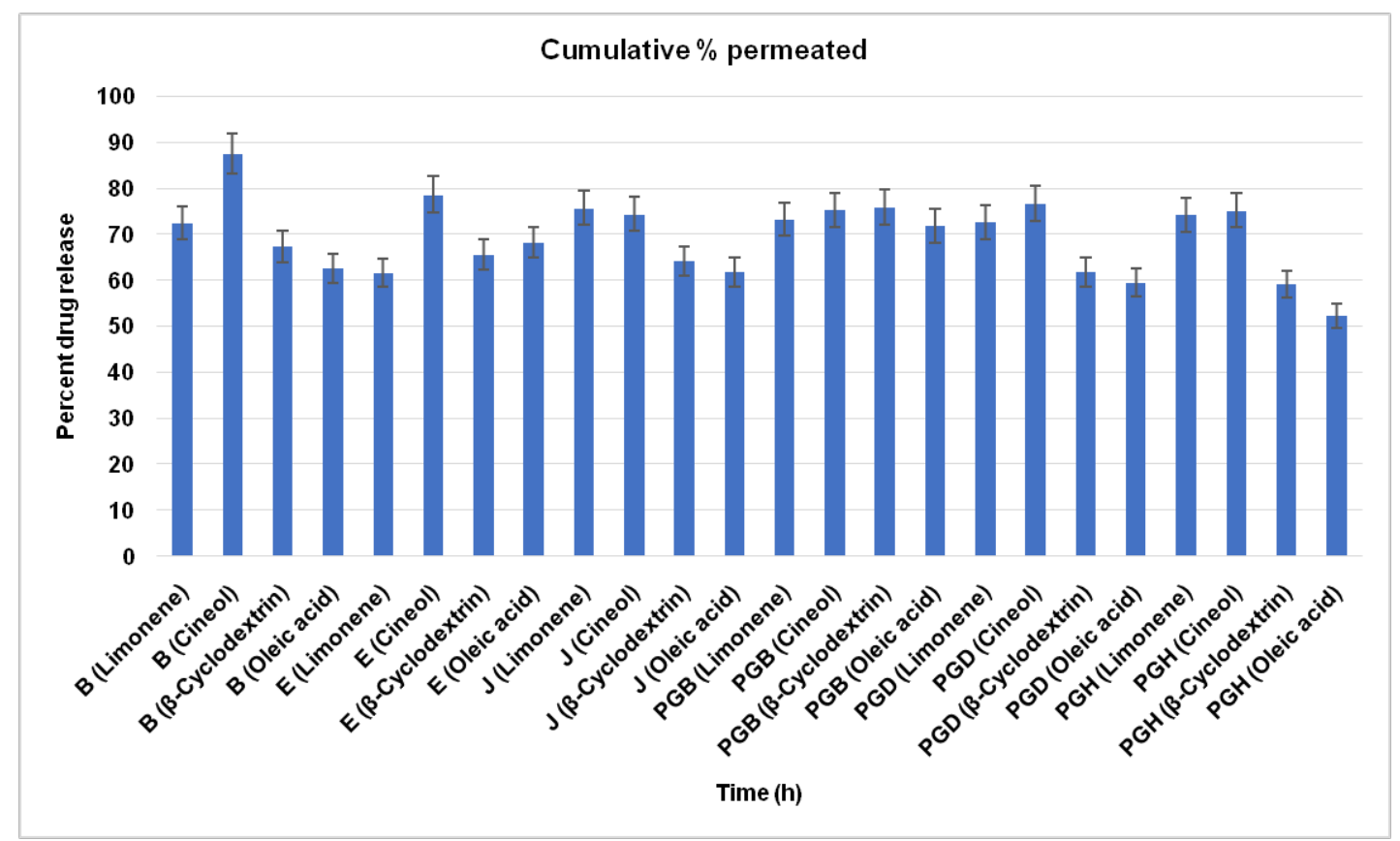

Fig. 3: Graph between time and percent drug release with different permeation enhancer (Results are expressed as mean \pm SD; $n=3$ ) 


\section{CONCLUSION}

In the present study, various formulation of transdermal patches was prepared using different polymers and penetration enhancers. The effect of penetration enhancers was studied. All the formulation showed good uniformity with regard to drug content and other parameters. On performing in vitro drug release, it was observed that maximum release obtained using cineol (natural) as penetration enhancer along with methocel $\mathrm{k} 15 \mathrm{~m}$ as a polymer. In conclusion, the delivery of the drug is promising and feasible with above-mentioned penetration enhancer with the specified polymer.

\section{ACKNOWLEDGMENT}

We here show our sincere gratitude to the companies for helping us by providing the gift samples. The gift samples of the drug received from dr. morepen and some excipients from the colorcon, same was acknowledged above.

\section{AUTHORS CONTRIBUTIONS}

All the author have contributed equally

\section{CONFLICT OF INTERESTS}

Declared none

\section{REFERENCES}

1. Hamid RM, Adrian CW, Brian WB. A lamellar matrix model for stratum corneum intercellular lipids. Effects of terpene penetration enhancers on the structure and thermal behavior of the matrix. Int J Pharm 1997;146:41-54.

2. Fuhrman Jr LC, Michniak BB, Behl CR, Malick AW. Effect of novel penetration enhancers on the transdermal delivery of hydrocortisone: an in vitro species comparison. J Controlled Release 1997;45:199-206.

3. Jia You F, Li Ren H, Yaw Bin H, Yi Hung T. Evaluation of transdermal iontophoresis of enoxacin from polymer formulations: in vitro skin permeation and in vivo microdialysis using wistar rat as an animal model. Int J Pharm 1999;180:137-49.

4. Victor MM, Clive SR. Inter-and intra-individual variability in human skin barrier function: a large scale retrospective study. Toxi In Vitro 2008;22:1062-9.

5. Yakov F, Gillian ME, Victor MM. Factors influencing hydrocortisone permeation into human hair follicles: use of the skin sandwich system. Int J Pharm 2008;358:144-50.

6. Taravat G, Parinaz Z, Hamed H, Ali N. The effect of penetration enhancers on drug delivery through the skin: a QSAR study. J Controlled Release 2004;99:113-25.

7. Jitendra B, Subhash P, Pathak AK. Development and optimization of the transdermal system of lisinopril dehydrate: employing permeation enhancers. Iran J Pharm Sci Aut 2010;6:245-51.

8. Indu V, Abdul A, Mohd A, Suraj PA. Investigating the potential of essential oils as a penetration enhancer for transdermal losartan delivery: effectiveness and mechanism of action. Asian J Pharm Sci 2014;9:260-7.

9. Vineet M, Yamini S, Mithun SR. Physical and chemical penetration enhancers in transdermal drug delivery system. Asian J Pharm 2010;7:173-83.

10. R Jayachandra B, Muralikrishnan D, Siva RV, Singh PN, Pandit JK. Cardiovascular effects of transdermally delivered bupranolol in rabbits: Effect of chemical penetration enhancers. Life Sci 2008;82:273-8.

11. Andega S, Kanikkannan N, Singh M. Comparison of the effect of fatty alcohols on the permeation of melatonin between porcine and human skin. J Controlled Release 2001;77:17-25.

12. Jin K, Sang Chul S. Controlled release of atenolol from the ethylene-vinyl acetate matrix. Int J Pharm 2004;273:23-7.

13. Udhumansha U, Molugu VSR, Kumaresan R, Roop KK, Farhan JA. The transdermal therapeutic system of carvedilol: effect of hydrophilic and hydrophobic matrix on in vitro and in vivo characteristics. AAPS PharmSciTech 2007;8:E1-8.

14. Chomchan A, ItsueI, Ken-ichi O, Kazutaka H, Toshikiro K. Skin permeation of propranolol from a polymeric film containing terpene enhancers for transdermal use. Int J Pharm 2005;289:167-78.

15. Reeta RG, Swantrant KJ, Manoj V. AOT water-in-oil microemulsions as a penetration enhancer in transdermal drug delivery of 5-fluorouracil. Colloids Surf B 2005;41:25-32.

16. Zainab AS, Nawal AR. Studying the effect of different variables on the formulation of mucoadhesive buccal patches of captopril. Int J Appl Pharm 2017;9:16-21.

17. Asha D, Abdul BA. Formulation and evaluation of transdermal patch of indomethacin containing patchouli oil as natural penetration enhancer. Asian J Pharm Clin Res 2017;10:320-5.

18. Khushpal K, Preetinder K, Sunny J, Upendra KJ. Formulation and in vitro evaluation of transdermal matrix patches of doxofylline. Asian J Pharm Clin Res 2016;9:140-5.

19. Andre LMR, Eduardo CF, Aline GP, Ana CZL, Magali BA, Gislaine $\mathrm{RP}$, et al. In vitro evaluation of transdermal nicotine delivery systems commercially available in Brazil. Brazil J Pharm Sci 2013;49. http://dx.doi.org/10.1590/S1984-82502013000300020.

20. Sadeghi AMM, Dorkoosh FA, Avadi MR, Weinhold M, Bayat A. Permeation enhancer effect of chitosan and chitosan derivatives: comparison of formulations as soluble polymers and nanoparticulate systems on insulin absorption in caco-2 cells. Eur J Pharm Biopharm 2008;70:270-8. 